\title{
LEVANTAMENTO E FLUTUAÇÃO POPULACIONAL DE CALLIPHORIDAE, EM CRIAÇÃO DE BOVINOS LEITEIROS, NO SUL DO RIO GRANDE DO SUL, BRASIL
}

\author{
Diego Moscarelli Pinto, ${ }^{1}$ Eduardo Bernardi,${ }^{2}$ Francielly Felchicher, ${ }^{2}$ \\ Juliana Hartleben da Costa, ${ }^{2}$ Cristine Ramos Zimmer ${ }^{2}$ e Paulo Bretanha Ribeiro ${ }^{3}$ \\ 1. Doutor em Fitossanidade, Universidade Federal de Pelotas (UFPel), Instituto de Biologia, \\ Departamento de Microbiologia e Parasitologia. \\ E-mail: dimoscarelli@yahoo.com.br. *Autor para correspondência. \\ 2. Departamento de Microbiologia e Parasitologia, Instituto de Biologia, UFPel. \\ 3. Doutor, professor titular, Departamento de Microbiologia e Parasitologia, Instituto de Biologia, UFPel.
}

RESUMO

Este estudo teve o objetivo de fornecer informações sobre o comportamento de califorídeos em local de criação de gado leiteiro, no Sul do Rio Grande do Sul. O trabalho foi realizado no Centro Agropecuário da Palma, pertencente à Universidade Federal de Pelotas (UFPEL). Para a captura dos califorídeos, utilizaram-se duas armadilhas do tipo WOT (Wind Oriented Trap), sendo estas iscadas com $250 \mathrm{~g}$ de fígado bovino em decomposição. As armadilhas foram expostas a cinquenta metros do local de ordenha durante sete dias por mês, entre os dias 10 e 20, e os espécimes capturados foram retirados das armadilhas e levados para o Laboratório de Biologia de Insetos para triagem, contagem e identificação. Durante o período de março de 2007 a fevereiro de 2008, capturaram-se 7.225 califorídeos, sendo Chrysomya megacephala a predominante, com 3.307 espécimens $(45,78 \%)$. No que diz respeito à distribuição mensal dos califorídeos encontrados em criação de bovinos leiteiros, no sul do Rio Grande do Sul, constata-se que, nos doze meses de coleta, houve uma variação mensal no número de espécies, sendo capturadas Chrysomya albiceps (2.445), Chrysomya putoria (90), Lucilia cuprina (118), Lucilia eximia (1.033), Lucilia sericata (41), Sarconesia chlorogaster (73), Calliphora lopesi (113), Hemilucilia semidiaphara (5).

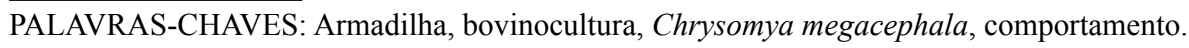

\section{ABSTRACT}

\section{SURVEY AND FLUCTUATION OF CALLIPHORIDAE POPULATION, IN DAIRY HERDS, IN THE SOUTH OF RIO GRANDE DO SUL, BRAZIL}

This study had as objective to provide information on the behavior of calliphorideos in places of dairy cattle rearing, in the south of the Rio Grande do Sul. The work was carried out in Centro Agropecuário da Palma, pertaining to Universidade Federal de Pelotas (UFPEL). For capturing the calliphorideos, two WOT (Wind Oriented Trap) traps, baited with $250 \mathrm{~g}$ of decomposition bovine liver were used. The traps were displayed at 50 meters from the milking place, seven days per month, within the $10^{\text {th }}$ and the $20^{\text {th }}$, and the captured specimens were removed from the traps and taken to the Laboratory of Insects Biology for selection, counting and identification. Within the period of March 2007 and the February 2008, 7,225 calliphorideos were captured, being Chrysomya megacephala the most predominant with 3.307 specimens $(45.78 \%)$. Considering the monthly distribution of the calliphorideos collected in dairy bovine herds for twelve months, in the South of Rio Grande do Sul, monthly variation in the num- 
ber of captured species was observed, being Chrysomya albiceps (2.445), Chrysomya putoria (90), Lucilia cuprina (118), Lucilia

KEY WORDS: Behavior, cattle, Chrysomya megacephala, trap.

\section{INTRODUÇÃO}

Conhecidas popularmente como "moscas varejeiras", as moscas da família Calliphoridae têm importante papel na natureza, participando da cadeia alimentar e da reciclagem da biomassa, podendo ainda veicular diversos agentes patogênicos que causam enfermidades parasitárias ao homem e aos animais domésticos. Atuam como agentes mecânicos e/ou biológicos, causadores de miíases (CARVALHO et al., 2003; FURUSAWA \& CASSINO, 2006), e, além disso, podem ser utilizadas em terapia larval (SHERMAN et al., 2000).

A família Calliphoridae é caracterizada por apresentar indivíduos de tamanho médio a grande $(4,0$ a 16,0 mm), abdome arredondado ou oval, de coloração escura, em sua maioria, com reflexos metálicos azulados, violáceos, esverdeados ou cúpreos, principalmente no tórax e abdome. Suas larvas possuem o corpo afilado na parte anterior, com fortes ganchos bucais, e truncado na parte posterior, onde se abrem as placas respiratórias (RODRIGUES-GUIMARÃES et al., 2004). Os califorídeos podem ser atraídos por substâncias em processo de fermentação, decomposição, sangue e feridas. Dessa forma, são encontrados em abatedouros, frigoríficos, curtumes, estábulos de gado leiteiro, aviários, feiras livres, frutos caídos, plantas em decomposição, lixo doméstico, aterros sanitários e em lixões a céu aberto (DIAS, 2008). Vários fatores podem influenciar a frequência de moscas em determinado ambiente. Conforme VIANNA et al. (2004), as interpéries climáticas são mais importantes no equilíbrio dessas populações; já os fatores bióticos exercem papel secundário.

Dada a importância desses dípteros, realizou-se este estudo com o objetivo de fornecer informações, para condução de futuros programas de controle, sobre a ocorrência e comportamento populacional de califorídeos em local de criação de gado leiteiro, no sul do Rio Grande do Sul.

\section{MATERIAL E MÉTODOS}

O trabalho foi realizado no Centro Agropecuário da Palma com 1.256 ha de área, pertencente à eximia (1.033), Lucilia sericata (41), Sarconesia chlorogaster (73), Calliphora lopesi (113), Hemilucilia semidiaphara (05).

Universidade Federal de Pelotas (UFPel), localizado no município de Capão do Leão, $\mathrm{RS}$, a quinze $\mathrm{km}$ da cidade de Pelotas, RS, à margem da BR 116, no km 535 , cujas coordenadas geográficas são $31^{\circ} 52^{\prime} 00^{\prime \prime}$ de latitude Sul e 52 $21^{\prime}$ ' 24" de longitude Oeste. Neste local, são desenvolvidas atividades com bovinos de leite, suínos e ovinos.

O período experimental foi de doze meses, entre março de 2007 e fevereiro de 2008. Para a captura dos Calliphoridae, empregaram-se duas armadilhas do tipo WOT (wind oriented trap - armadilha orientada pelo vento) (Figura 1). Como iscas, usaram-se $250 \mathrm{~g}$ de fígado bovino em decomposição, os quais eram colocados em um recipiente de plástico.

As armadilhas foram confeccionadas artesanalmente de acordo com o modelo de BROCE et al. (1977), modificado por OLIVEIRA (1980). Cada armadilha constituiu-se de um balde plástico de cor amarela com capacidade para oito litros, sendo removido o fundo, adaptando-se uma peneira plástica removível, que permitia a retirada dos espécimes coletados e também a colocação do recipiente com a isca. Na alça do balde foi anexada uma aleta de metal (alumínio) para direcionar a abertura do balde no sentido do vento. $\mathrm{Na}$ borda do balde, colocou-se um telado plástico com uma pequena abertura, tipo cone invertido, que permitia a entrada dos espécimes na armadilha.

$\mathrm{Na}$ parte inferior da armadilha, colocaram-se recipientes que funcionavam como contrapesos para evitar o movimento de pêndulo. As armadilhas foram amarradas, com cordas, em galhos de árvores a uma altura de cerca de 1,2 $\mathrm{m}$ do solo.

As armadilhas ficaram expostas a cinquenta metros do local de criação de suínos e do local de ordenha dos bovinos durante sete dias por mês, entre os dias 10 e 20 de cada mês. Retiraram-se os espécimes das armadilhas através de sacos plásticos de sessenta litros, os quais eram posteriormente levados para o Laboratório de Biologia de Insetos para triagem, contagem e identificação. A identificação foi feita com base na chave dicotômica das espécies (CARVALHO \& RIBEIRO, 2000). 


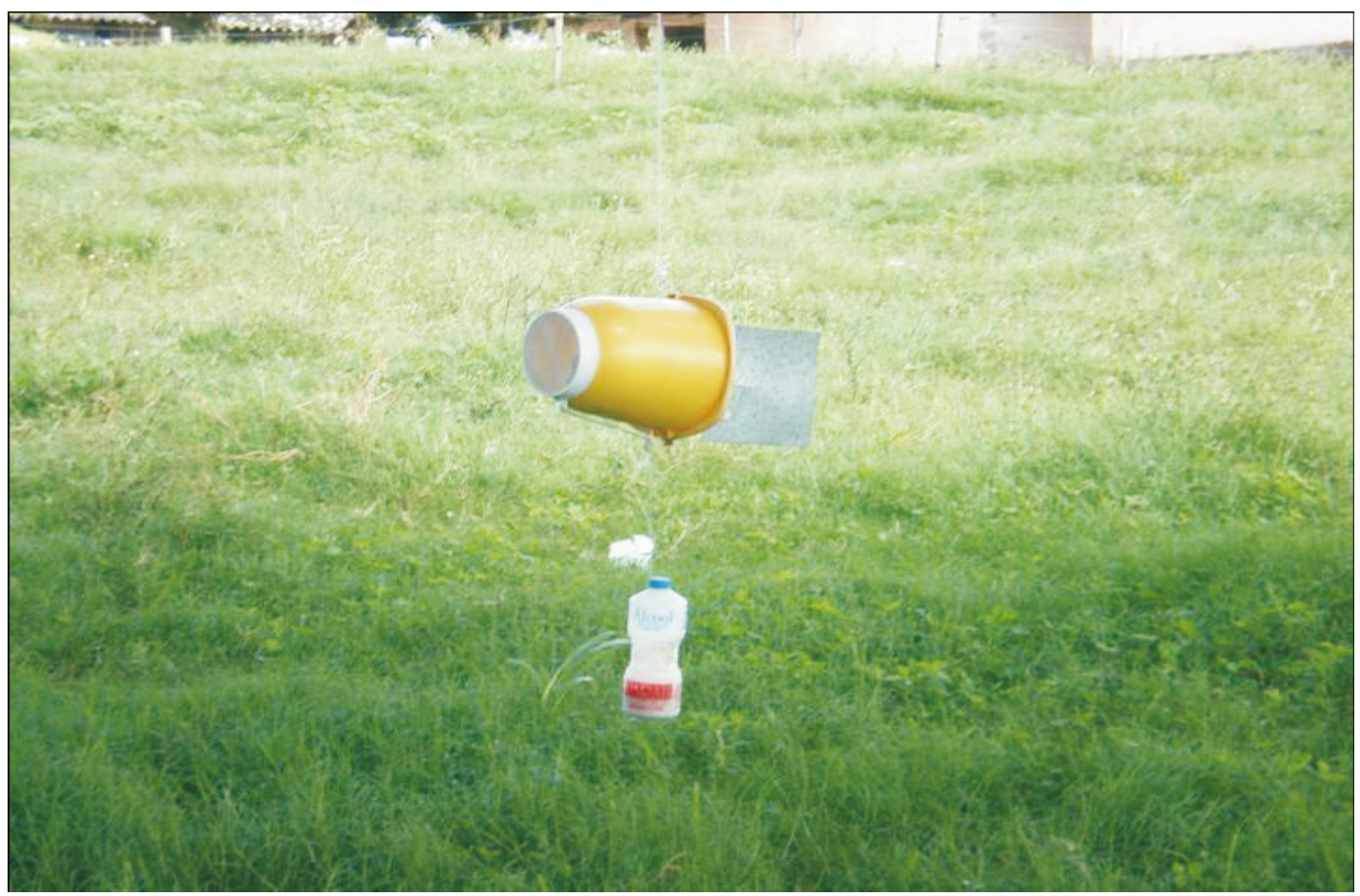

FIGURA 1. Armadilha WOT (Wind Oriented Trap - armadilha orientada pelo vento).

Os dados meteorológicos de temperatura média mensal e precipitação pluviométrica foram obtidos na Estação Agroclimatologia da Universidade Federal de Pelotas. Submeteram-se os resultados obtidos à analise de regressão polinomial, utilizando-se o programa estatístico SANEST (ZONTA \& MACHADO, 1984).

\section{RESULTADOS E DISCUSSÃO}

Durante o período experimental, foram capturados 7.225 califorídeos, sendo a espécie Chrysomya megacephala predominante, com 3.307 espécimens $(45,78 \%)$ (Tabela 1$)$.

Na Figura 2, pode-se observar que a temperatura média mensal variou de $9,9{ }^{\circ} \mathrm{C}$ (julho) a $23,3{ }^{\circ} \mathrm{C}$ (março) e a precipitação pluviométrica acumulada mensal oscilou de 35,2 mm (abril) a 226,4 mm (junho). $\mathrm{Na}$ Figura 3, pode-se verificar que a velocidade média mensal do vento variou de $1,7 \mathrm{~m} \cdot \mathrm{s}^{-1}$ (abril) a 2,6 m.s $\mathrm{s}^{-1}$ (outubro e janeiro). Levando-se em consideração a distribuição mensal dos califorídeos, constata-se que, nos doze meses de coleta, houve uma variação mensal no número de espécies capturadas.
TABELA 1. Frequência das espécies de Calliphoridae capturados em armadilha WOT, em criação de gado leiteiro, no período de março de 2007 a fevereiro de 2008, em Pelotas, RS

\begin{tabular}{lcc}
\hline \multicolumn{1}{c}{ Espécies } & $\begin{array}{c}\text { Frequência absoluta } \\
\left(\mathrm{n}^{\mathbf{0}}\right)\end{array}$ & $\begin{array}{c}\text { Frequência relativa } \\
(\%)\end{array}$ \\
\hline $\begin{array}{l}\text { Chrysomya albiceps } \\
\text { Chrysomya } \\
\text { megacephala }\end{array}$ & 2445 & 33,84 \\
Chrysomya putoria & 3307 & 45,78 \\
$\begin{array}{l}\text { Lucilia cuprina } \\
\text { Lucilia eximia }\end{array}$ & 90 & 1,25 \\
$\begin{array}{l}\text { Lucilia sericata } \\
\text { Sarconesia } \\
\text { chlorogaster }\end{array}$ & 118 & 1,64 \\
Calliphora lopesi & 41 & 14,3 \\
$\begin{array}{l}\text { Hemilucilia } \\
\text { semidiaphara }\end{array}$ & 73 & 0,56 \\
Total & 113 & 1,01 \\
\hline
\end{tabular}




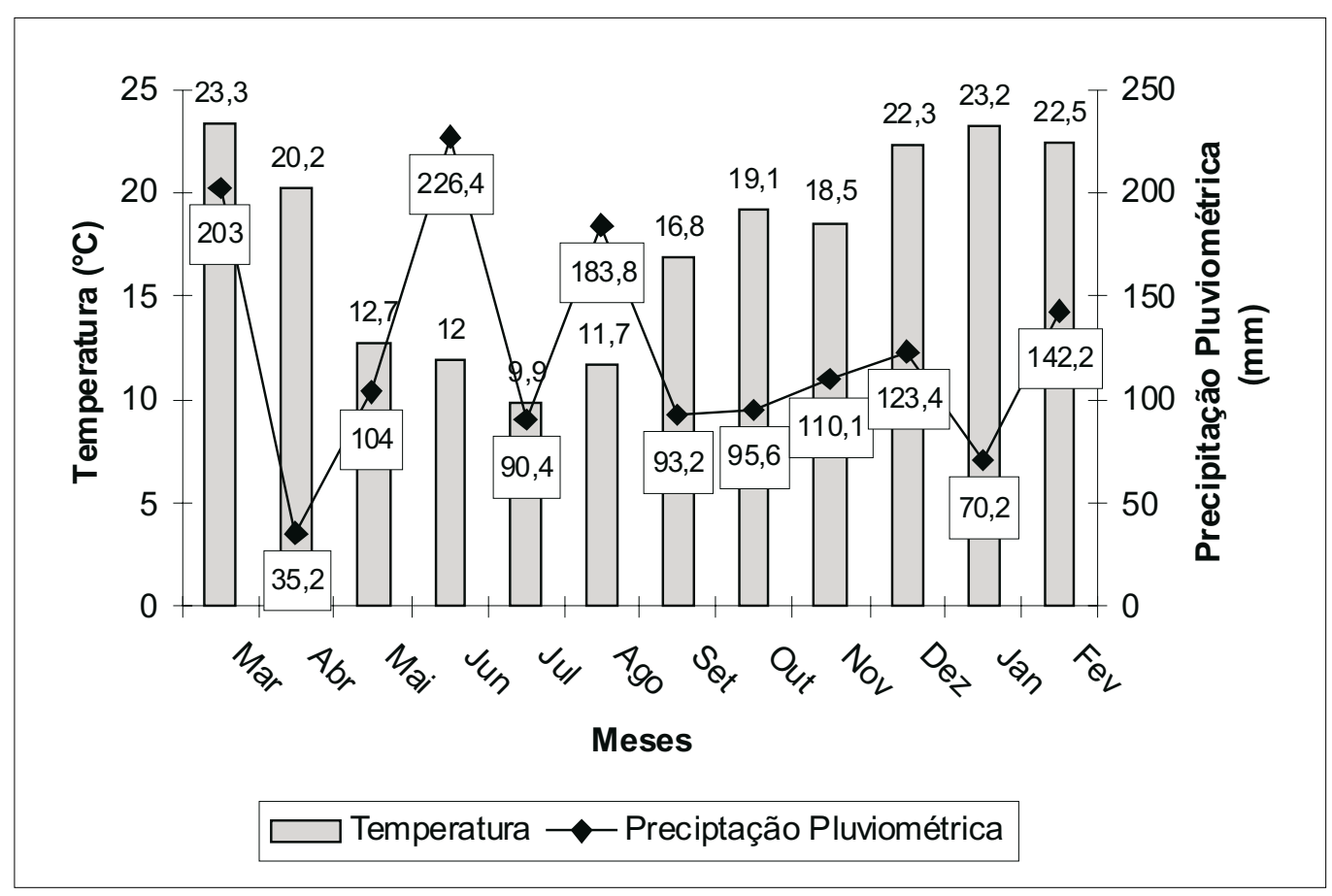

FIGURA 2. Temperatura média mensal e precipitação pluviométrica, no período de março de 2007 a fevereiro de 2008, no sul do Rio Grande do Sul (Estação Agroclimatológica da Universidade Federal de Pelotas).

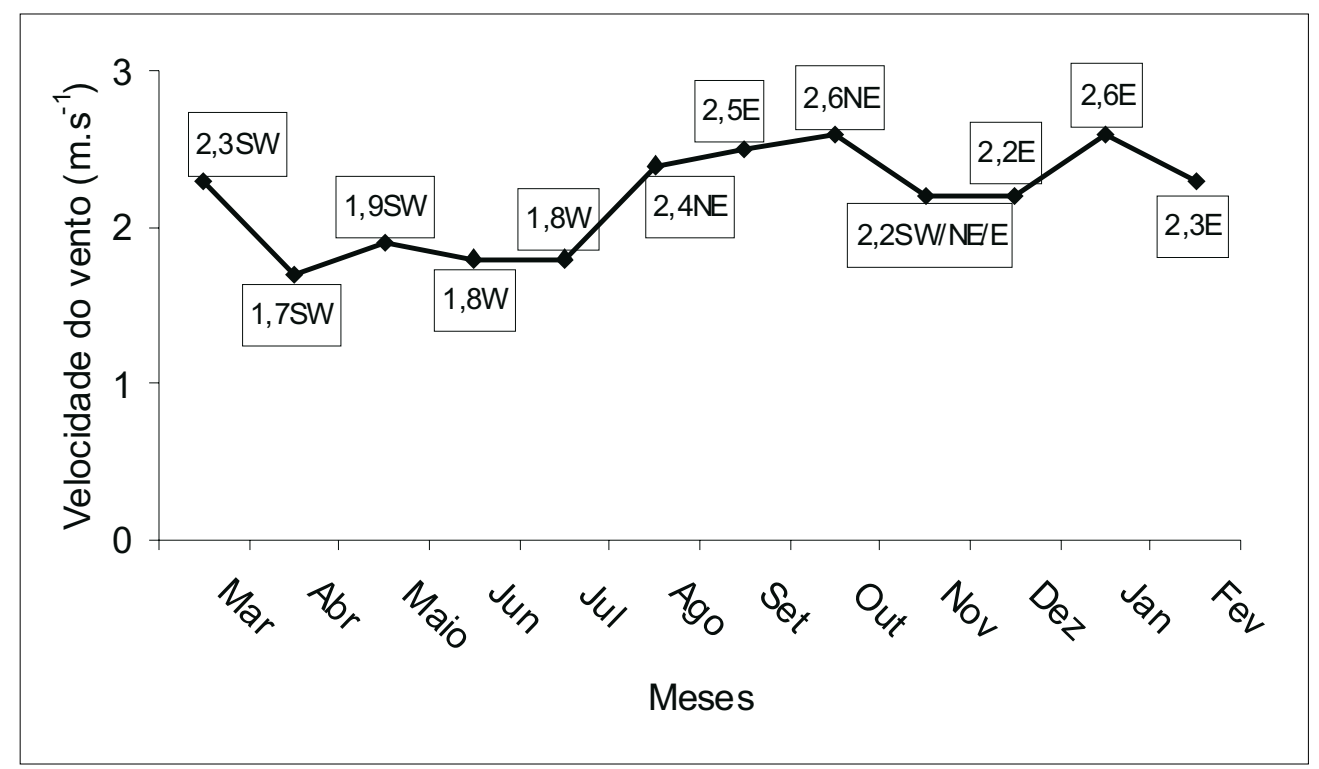

FIGURA 3. Velocidade média mensal, no período de março de 2007 a fevereiro de 2008, no sul do Rio Grande do Sul (Estação Agroclimatológica da Universidade Federal de Pelotas).

A espécie C. megacephala esteve presente em sete dos doze meses de coleta, sendo possível observar o comportamento dos adultos. O maior número de espécimens capturadas ocorreu no mês de abril (2.544) (Tabela 2) (Figura 4), sendo que esse mês apresentou temperatura média mensal de $20,2{ }^{\circ} \mathrm{C}$ (Figura 2). $\mathrm{O}$ menor índice de coleta ocorreu no mês de junho (1), sendo que este mês apresentou temperatura média mensal de $12^{\circ} \mathrm{C}$ (Figura 2). Nos meses de julho, agosto, setembro, outubro e janeiro não houve captura. 
A Tabela 2 ilustra a ocorrência mensal dos califorídeos. Nela, pode-se observar que, nos doze meses de coleta, nenhuma espécie esteve presente em todos os meses e que em apenas três meses não houve captura dos dípteros.

TABELA 2. Espécies de Calliphoridae, capturadas em criação de bovinos leiteiros, no período de março de 2007 a fevereiro de 2008, em Pelotas, RS

\begin{tabular}{|c|c|c|c|c|c|c|c|c|c|c|c|c|c|c|}
\hline \multirow{2}{*}{ E } & \multirow{2}{*}{ Família/Espécies* } & \multicolumn{13}{|c|}{ Meses (2007/2008) } \\
\hline & & Mar. & Abr. & Maio & Jun. & Jul. & Ago. & Set. & Out. & Nov. & Dez. & Jan. & Fev. & Total \\
\hline \multicolumn{15}{|c|}{ Calliphoridae } \\
\hline \multirow{9}{*}{ 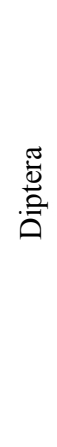 } & Chrysomya albiceps & 104 & 1.780 & 289 & - & - & - & - & - & 24 & 1 & - & 247 & 2.445 \\
\hline & Chrysomya megacephala & 102 & 2.544 & 230 & 1 & - & - & - & - & 126 & 2 & - & 302 & 3.307 \\
\hline & Chrysomya putoria & 5 & 59 & 2 & - & - & - & - & - & 20 & - & - & 04 & 90 \\
\hline & Lucilia cuprina & 4 & 33 & 1 & - & - & - & - & 1 & 43 & 2 & - & 34 & 118 \\
\hline & Lucilia eximia & 24 & 301 & 104 & 17 & - & - & 27 & - & 392 & 12 & - & 156 & 1.033 \\
\hline & Lucilia sericata & - & 17 & - & - & - & - & - & - & 24 & - & - & - & 41 \\
\hline & Sarconesia chlorogaster & 1 & 2 & 2 & - & - & - & 2 & - & 54 & 3 & - & 09 & 73 \\
\hline & Calliphora lopesi & - & 27 & 5 & - & - & - & 22 & - & 58 & - & - & 01 & 113 \\
\hline & Hemilucilia semidiaphara & - & - & - & - & - & - & - & - & 5 & - & - & - & 5 \\
\hline \multicolumn{2}{|c|}{ Total } & 240 & 4.763 & 633 & 18 & 0 & 0 & 51 & 1 & 746 & 20 & 0 & 753 & 7.225 \\
\hline
\end{tabular}

* Os dados estatísticos não foram descritos, porque os resultados não apresentarem diferenças significativas.

VIANNA et al. (2004), avaliando a ocorrência e flutuação populacional de espécies de Chrysomya em Pelotas, RS, também verificaram uma grande ocorrência dessa espécie, sendo a segunda mais capturada em armadilhas WOT e com pico populacional no outono, com influência da temperatura. Esses resultados também são similares aos obtidos por COSTA et al. (1992), os quais indicaram que a população das espécies de Chrysomya, em Capão do Leão, RS, reduziu-se nos períodos com temperaturas baixas ou elevadas, alcançando pico populacional no outono. Segundo LEANDRO \& D'ALMEIDA (2005), a isca de peixe, usada para capturar moscas no Jardim Botânico, RJ, resultou em 41.080 dípteros capturadas, sendo Chrysomya megacephala a espécie mais abundante, representando 69,34\%, dos espécimens capturados. Para AZEVEDO (2006), essa espécie é bastante abundante em todas as áreas na região de Pelotas, RS, tendo maior ocorrência nos meses mais quentes.

Chrysomya albiceps ocorreu durante seis dos doze meses de coletas, apresentando seu acme populacional no mês de abril (1.780), sendo que esse mês apresentou temperatura média mensal de $20,2^{\circ} \mathrm{C}$ (Figura 2). O menor índice de coleta ocorreu no mês de dezembro (1), com temperatura média mensal de
22,3 ${ }^{\circ} \mathrm{C}$. Nos meses de junho, julho, agosto, setembro, outubro e janeiro não houve captura (Tabela 2) (Figura 4).

Assim como neste trabalho, LEANDRO \& D'ALMEIDA (2005) determinaram que C. albiceps foi a segunda espécie mais coletada, com 546 exemplares, em um fragmento de mata na Ilha do Governador no Rio de Janeiro. Outro fator que provavelmente contribui para a sua alta abundância foi o fato de a espécie ser uma k-estrategista, com larvas incorporando de forma máxima o alimento, em um período curto de tempo. Essa espécie é bastante abundante na região de Pelotas, RS, com pico populacional no outono e com redução ou ausência da população de junho a novembro, mostrando que a temperatura é um fator importante na flutuação dessa espécie (VIANNA et al., 2004; AZEVEDO, 2006).

O díptero Chrysomya putoria ocorreu com maior frequência no mês de abril (59), em que se registrou uma temperatura média mensal de $20,2^{\circ} \mathrm{C}$. A menor ocorrência dessa espécie deu-se no mês de maio (2), com temperatura de $12,7^{\circ} \mathrm{C}$. Em junho, julho, agosto, setembro, outubro, dezembro e janeiro essa espécie não esteve presente (Tabela 2) (Figura 4). Esse resultado é semelhante ao de AZEVEDO (2006), que, 
avaliando a dinâmica populacional dessa espécie em Pelotas, RS, também verificou seu pico populacional no mês de abril. Já VIANNA et al. (2004), na mesma região, registraram um pico populacional dessa espécie no mês de março, que é também no outono.

COSTA et al. (1992), avaliando a flutuação populacional de califorídeos em Capão do Leão, RS, verificaram que $C$. putoria é a segunda espécie que mais ocorre juntamente com $C$. megacephala. Em contrapartida, em um levantamento de califorídeos na mata da Ilha do Governador, RJ, C. putoria foi a espécie menos abundante do gênero (LEANDRO \& D' ALMEIDA, 2005).

A espécie Lucilia cuprina apresentou pico populacional no mês de novembro (43), com temperatura média mensal de $18,5^{\circ} \mathrm{C}$. O menor número de espécimens capturados ocorreu nos meses de maio e outubro (2), com temperaturas de $12,7^{\circ} \mathrm{C}$ e $19,1^{\circ} \mathrm{C}$, respectivamente. Em junho, julho, agosto, setembro e dezembro esse díptero não esteve presente (Tabela 2) (Figura 4). Esse resultado difere do encontrado por outros autores, que não obtiveram registro da ocorrência dessa espécie em ambiente silvestre, apenas em ambiente urbano, o que se deve, provavelmente, à ausência de fezes em decomposição no ambiente silvestre analisado, uma vez que essa espécie se caracteriza por visitar fezes em decomposição para reprodução (LEANDRO \& D'ALMEIDA, 2005; AZEVEDO, 2006).

Lucilia eximia também apresentou pico populacional no mês de novembro (392), com temperatura média mensal de $18,5^{\circ} \mathrm{C}$. O menor número de espécimens capturados ocorreu no mês de dezembro (12), quando a temperatura média mensal foi de $22,3^{\circ} \mathrm{C}$. Esse díptero não esteve presente nos meses de julho, agosto, outubro e janeiro (Tabela 2) (Figura 4). Diferentemente deste trabalho, AZEVEDO (2006), ao longo de seu experimento, em Pelotas, RS, verificou que $L$. eximia foi a espécie com maior frequência, representando $46,45 \%$ dos califorídeos capturados. Resultados semelhantes foram encontrados no Rio de Janeiro (MARINHO et al., 2003).

Lucilia sericata ocorreu apenas em dois dos doze meses de captura, com dezessete espécimens capturados no mês de abril e 24 no mês de novembro, com temperaturas médias mensais de $20,2^{\circ} \mathrm{C}$ e $18,5^{\circ} \mathrm{C}$, respectivamente. Esse resultado difere do obtido por AZEVEDO (2006), em que L. sericata apresentou ocorrência nos meses de outubro, novembro, março e junho, tendo seus picos nos meses de outubro e março.

Sarconesia chlorogaster apresentou pico populacional no mês de novembro (54), com temperatura média mensal de $18,5^{\circ} \mathrm{C}$ e a menor ocorrência se deu no mês de março (1), em que a temperatura média mensal foi de $23,3{ }^{\circ} \mathrm{C}$. Nos meses de junho, julho, agosto, outubro e janeiro não houve captura dessa espécie. Em trabalho realizado por AZEVEDO (2006), em Pelotas, RS, S. chlorogaster esteve presente de agosto a dezembro, com pico populacional nos meses de outubro e dezembro, diferentemente deste trabalho, cujo pico populacional ocorreu no mês de novembro.

Calliphora lopesi apresentou pico populacional no mês de novembro, com temperatura média mensal de $18,5^{\circ} \mathrm{C}$, e menor ocorrência no mês de fevereiro (1), quando a temperatura média mensal foi de $22,5^{\circ} \mathrm{C}$. Nos meses de março, junho, julho, agosto, dezembro e janeiro, a espécie não esteve presente. Esse resultado difere parcialmente do obtido por AZEVEDO (2006), em que $C$. lopesi ocorreu durante todo o ano, com exceção do mês de fevereiro, e com os maiores picos nos meses de setembro, outubro e junho.

A flutuação mensal de espécies da família Calliphoridae capturadas no período de março de 2007 a fevereiro de 2008 pode ser observada na Figura 4. Pela análise de regressão, o modelo quadrático foi significativo $(0,001 \%)$.

Hemilucilia semidiaphara esteve presente apenas no mês de novembro (5), com temperatura média mensal de $18,5^{\circ} \mathrm{C}$. Dadas a baixa densidade populacional e a frequência mensal, não foi estimada a flutuação populacional desta espécie. Entretanto, em trabalho realizado por AZEVEDO (2006), sua ocorrência foi registrada de setembro a dezembro, com temperaturas entre $13^{\circ} \mathrm{C}$ e $24,5^{\circ} \mathrm{C}$, com pico em novembro.

Em trabalho realizado por BATISTA (1987), no campus da Universidade Federal de Pelotas, para determinar a flutuação populacional de dípteros capturados em armadilhas WOT a família Calliphoridae comportou-se com maior ocorrência no mês de abril e menor no mês de janeiro, resultado semelhante ao encontrado no presente trabalho. 


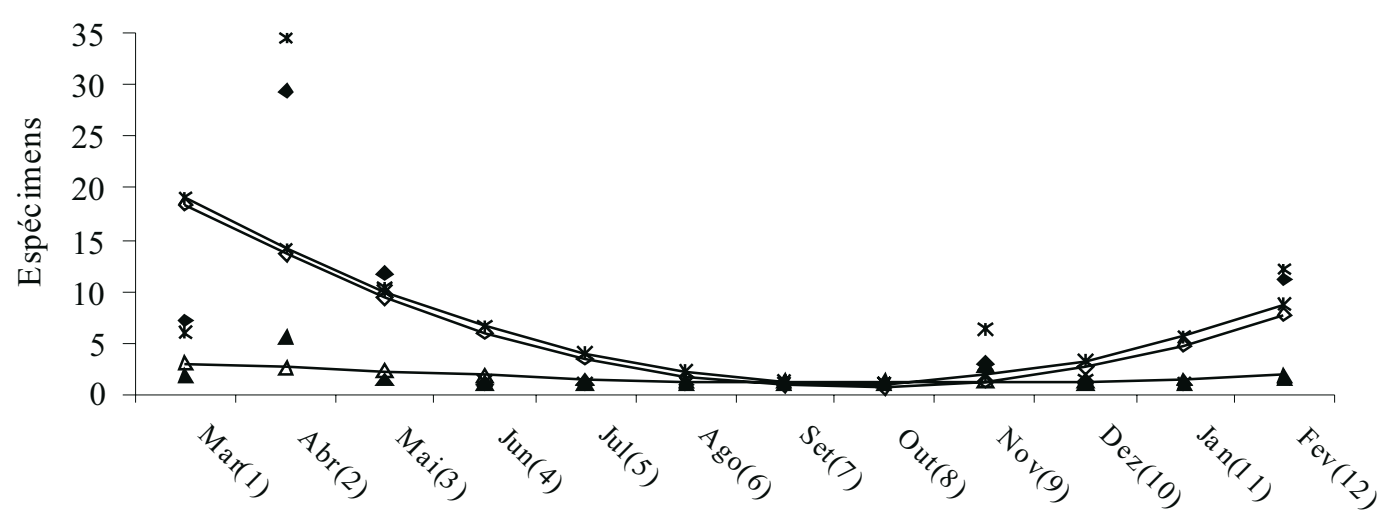

Meses

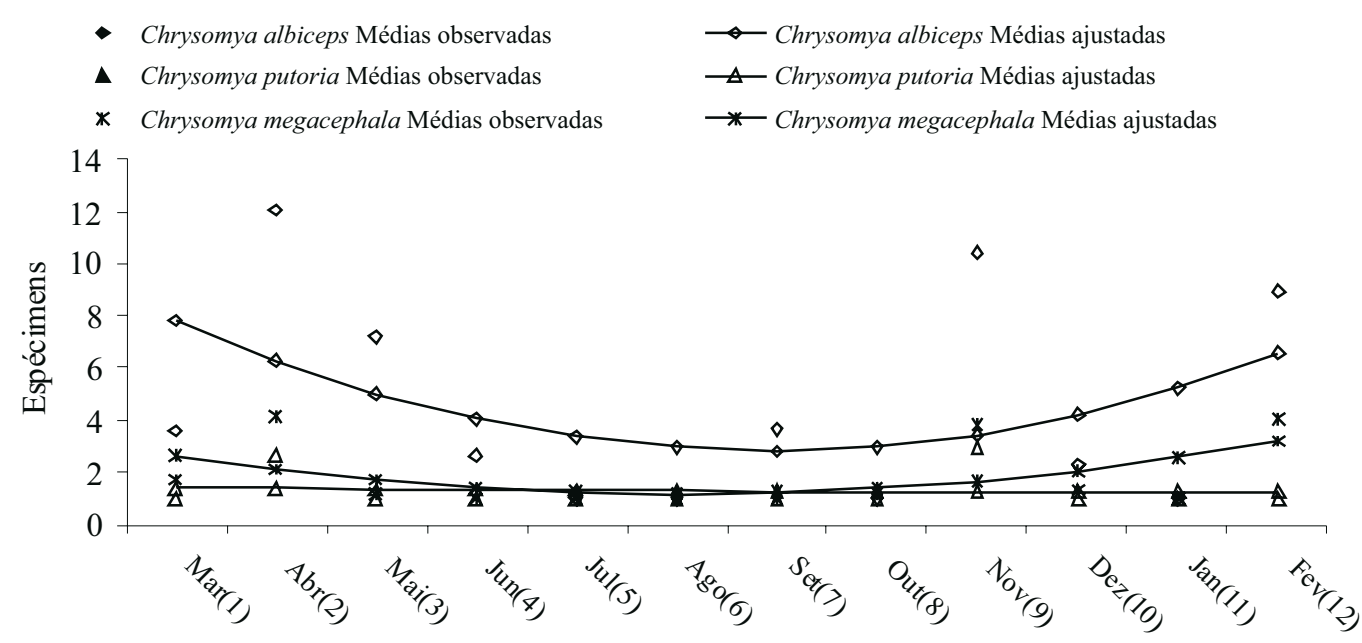

Meses

$\diamond \quad$ Lucilia eximia Médias observadas

$\Delta \quad$ Lucilia sericata Médias observadas

* Lucilia cuprina Médias observadas
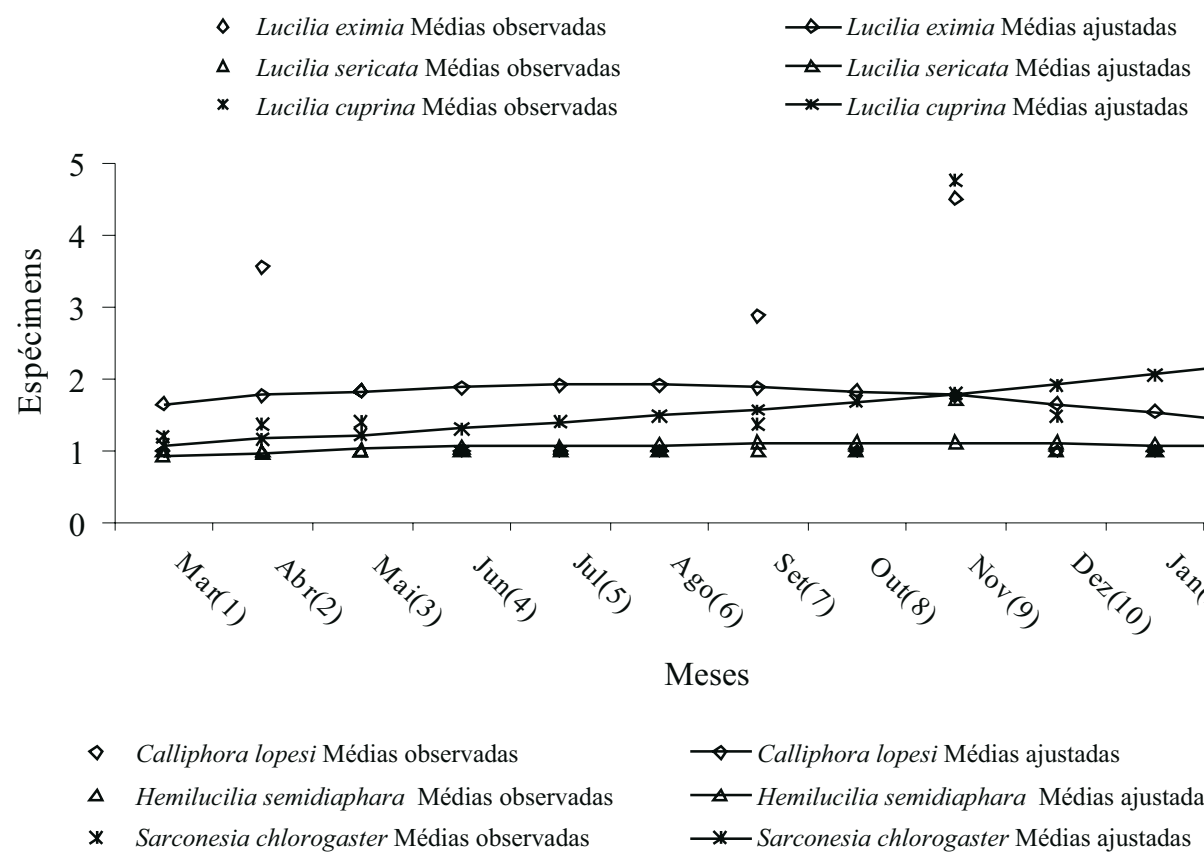

*
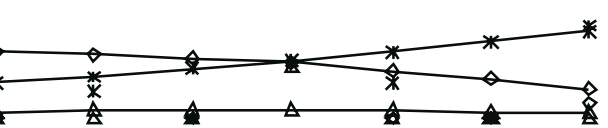

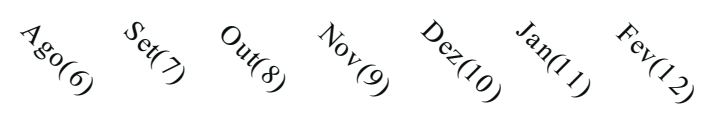

Meses

FIGURA 4. Flutuação populacional de Calliphoridae, capturadas em armadilhas WOT, em criação de bovinos leiteiros, no período de março de 2007 a fevereiro de 2008, em Pelotas, RS 
Levando-se em consideração a distribuição mensal dos califorídeos em criação gado leiteiro, no sul do Rio Grande do Sul, constatou-se que houve uma variação mensal no número de espécies capturadas, sendo o mês de abril o que apresentou o maior número de indivíduos capturados com uma combinação de elevada temperatura média mensal $\left(20,2^{\circ} \mathrm{C}\right)$ e baixa precipitação pluviométrica $(35,2 \mathrm{~mm})$. Em avaliação da Tabela 2, pode-se verificar que, nos meses de março, abril e maio (final do verão e início do outono), as populações se mantêm altas, pois a temperatura em declínio promove o aumento da longevidade dos dípteros. Temperaturas que propiciam menor intervalo entre gerações determinam altas densidades populacionais (GALLO et al., 2006).

Nos meses de julho e agosto não houve captura, em virtude das baixas temperaturas, aliadas à alta precipitação pluviométrica. No mês de setembro, com o aumento das temperaturas médias mensais, tem início o restabelecimento da população, o que se reflete nos picos populacionais no verão. Já no mês de janeiro, a não captura dos califorídeos pode ter ocorrido em virtude da elevada temperatura, combinada com baixa precipitação pluviométrica, o que faz com que as fezes sequem mais rapidamente, inviabilizando ovos e larvas (Tabela 2) (Figura 2) (Figura 4).

A captura de apenas um indivíduo no mês de outubro e nenhum no mês de janeiro pode também estar relacionada com a maior velocidade média do vento nesses meses $\left(2,6 \mathrm{~m} \cdot \mathrm{s}^{-1}\right)$, uma vez que o movimento exagerado da armadilha, com a força do vento, pode dificultar a localização do atrativo, pelos califorídeos, diminuindo a entrada deles na armadilha.

A análise de regressão polinomial para todas as espécies indicou o modelo quadrático como o que melhor se ajustou aos dados de flutuação populacional. Em biologia, esse modelo é bastante usado para explicar as relações entre variáveis que exprimem características de sistemas na natureza e que não são exatas, como neste experimento, em que as médias de captura oscilaram, durante o período experimental, principalmente em virtude da variação de temperatura.

\section{CONCLUSÕES}

De acordo com os resultados obtidos, nas condições destes experimentos, pode-se concluir que:
- as nove espécies califorídeos encontrados na região de Capão do Leão, RS, são associadas à criação de bovinos leiteiros;

- o gênero Chysomya foi o predominante, com as seguintes espécies: C. megacephala, C. albiceps e C. putoria;

- Chrysomya megacephala foi a espécie dominante em criação de bovinos leiteiros;

- a maior abundância e diversidade de califorídeos ocorreram nos meses de abril, maio, novembro e fevereiro;

- o modelo de flutuação populacional mensal circanual de califorídeos é influenciado principalmente pela temperatura.

\section{REFERÊNCIAS}

AZEVEDO, R. R. Calliphoridae (Insecta: Diptera) da região de Pelotas, Rio Grande do Sul, Brasil: uma analise da dinâmica populacional. 2006. 47 f. Monografia (Licenciatura e Bacharelado em Ciências Biológicas) - Universidade Federal de Pelotas, Pelotas, RS, 2006.

BATISTA, Z. R. Ocorrência e distribuição de larvas de Dermatobia hominis (L. Jr. 1781) em bovinos e flutuação populacional de dípteros sinantrópicos rurais. 1987. 70 f. Dissertação (Mestrado em Medicina Veterinária Preventiva) - Faculdade de Veterinária, Universidade Federal de Pelotas, 1987.

BROCE, A. B.; GOODENOUGH, J. L.; COPPEDGE, J. R. A wind oriented trap for screwworm flies. Journal of Economic Entomology, v. 70, n. 4, p. 413-416, 1977.

CARVALHO, C. J. B. de; BORTOLANZA, M.; CARDOSO da SILVA, M.C.; SOARES, E.D.G. Distributional patterns of the neotropical Muscidae (Dipetra). In: MORRONE, J. J.; LLORENTE, J. (Edit.) Uma perspectiva latinoamericana de la biogeografia. Mexico: Las Prensas de Ciencias, UNAM, 2003. p. 263-274.

CARVALHO, C. J. B.; RIBEIRO, P. B. Chave de identificação das espécies de Calliphoridae (Diptera) do sul do Brasil. Revista Brasiléia de Parasitologia Veterinária, v. 9, p. 169-173, 2000.

COSTA, P. R. P.; WIEGAND, M. M.; BRUM, J. G. W.; RIBEIRO, P. B. Flutuação populacional das espécies de Chrysomya (Diptera, Calliphoridae) no Município do Capão do Leão, RS. Arquivo Brasileiro de Medicina Veterinária e Zootecnia, v. 44, n. 4, p. 289-296, 1992.

DIAS, L. S. Biodiversidade de moscas Calliphoridae e Muscidae no depósito de lixo urbano de Presidente Prudente, São Paulo, Brasil. 2008. 40 f. Dissertação (Mestrado em Ciência Animal) Faculdade de Veterinária, Universidade do Oeste Paulista, 2008. 
FURUSAWA, G. P.; CASSINO, P. C. R. Ocorrência e distribuição de Calliphotidae (Diptera, Oestroidea) em um fragmento de Mata Atlântica Secundária no Município de Engenheiro Paulo de Frontin, Médio Paraíba, RJ. Revista de Biologia e Ciências da Terra, v. 6, n. 1, p. 152-164, 2006.

GALLO, D.; NAKANO, O.; SILVEIRA-NETO, S.; CARVALHO, R. P. L.; BAPTISTA, G. C.; BERTI-FILHO, E.; PARRA, J. R. P.; ZUCCHI, R. A.; ALVES, S. B.; VENDRAMIM, J. D.; MARCHINI, L. C.; LOPES, J. R. S.; OMOTO, C. Entomologia agrícola. Piracicaba: FEALQ, 2006. v. 10, 920 p.

LEANDRO, M. J. F.; D'ALMEIDA, J. M. Levantamento de Calliphoridae, Fanniidae, Muscidae e Sarcophagidae em um fragmento de mata na Ilha do Governador, Rio de Janeiro, Brasil. Iheringia, v. 95 , n. 4 , p. 377-381, 2005.

MARINHO, C. R.; AZEVEDO,A. C. G.; AGUIAR-COELHO, V. M. Diversidade de califorídeos (Diptera, Calliphoridae) em área urbana, Rio de Janeiro. Entomologia y Vetores, v. 10, p. 185-199, 2003.

OLIVEIRA, C. M. B. Biologia, flutuação populacional e patologia de Cochliomyia hominivorax (Coquerel, 1858) (Diptera,
Calliphoridae). 1980. 100 f. Tese (Doutorado em Entomologia) - Universidade Federal Rural do Rio de Janeiro, 1980.

RODRIGUES-GUIMARÃES, R.; MOYABORJA, G. E.; PILE, E. A.; GUIMARÃES, R. R.; SAMPAIO, F. R. Constance coefficient of blowflies (Diptera: Calliphoridae) in Nova Iguaçu, Rio de Janeiro, Brazil. Boletin de la Sociedad Entomológica Aragonesa, v. 35, p. 251-255, 2004.

SHERMAN, R. A.; HALL, M. J. R.; THOMAS, S. Medicinal maggots: an ancient remedy for some contemponary afflictions. Annual Review of Entomology, v. 45, p. 55-81, 2000.

VIANNA, E. E. S.; COSTA, P. R. P.; FERNANDES, A. L.; RIBEIRO, P. B. Abundância e flutuação das espécies de Chrysomya (Diptera, Calliphoridae) em Pelotas, Rio de Grande do Sul. Iheringia Serie Zoologia, v. 94, n. 3, p. 231-234, 2004.

ZONTA, E. P.; MACHADO, A. A. Sanest: sistema de análise estatística para microcomputadores. Registrado na Secretaria Especial de Informática sob no .066060 - categoria A. Pelotas: Universidade Federal de Pelotas, 1984. 138 p. 